\title{
NATURAL CONVECTION IN A DIFFERENTIALLY HEATED ENCLOSURE WITH TRIANGULAR ROOF
}

\author{
Sumon Saha*, Noman Hasan and Chowdhury Md. Feroz \\ Department of Mechanical Engineering, \\ Bangladesh University of Engineering and Technology, Dhaka-1000, Bangladesh. \\ *Email: sumonsaha@me.buet.ac.bd
}

\begin{abstract}
A numerical study has been carried out for laminar natural convection heat transfer within a two-dimensional modified square enclosure having a triangular roof. The vertical sidewalls are differentially heated considering a constant flux heat source strip is flush mounted with the left wall. The opposite wall is considered isothermal having a temperature of the surrounding fluid. The rest of the walls are adiabatic. Air is considered as the fluid inside the enclosure. The solution has been carried out on the basis of finite element analysis by a non-linear parametric solver to examine the heat transfer and fluid flow characteristics. Different heights of the triangular roof have been considered for the present analysis. Fluid flow fields and isotherm patterns and the average Nusselt number are presented for the Rayleigh numbers ranging from $10^{3}$ to $10^{6}$ in order to show the effects of these governing parameters. The average Nusselt number computed for the case of isoflux heating is also compared with the case of isothermal heating as available in the literature. The outcome of the present investigation shows that the convective phenomenon is greatly influenced by the inclined roof height.
\end{abstract}

Keywords: Natural convection, triangular roof, Rayleigh number, isoflux heating.

\section{INTRODUCTION}

Natural convection heat transfer and fluid flow in enclosed space or closed cavities has received considerable attention because of its importance in several thermal engineering problems. Applications are found in the design of electronic devices, solar thermal receivers, uncovered flat plate solar collectors having rows of vertical strips, geothermal reservoirs, crystal growth etc. For an enclosure, if the vertical walls are in different heated state and the bottom and the top walls are adiabatic, the fluid flow occurs due to the presence of a horizontal temperature difference. The density difference gradient is horizontal as well as the temperature difference gradient whereas the gravitational force acts perpendicularly downward. The gravity vector and the gradient vector act normal to each other and hence their orientation decides the direction of circulation in the cavity.

Flow inside an enclosure is much more complicated to investigate, as the boundary zone and the middle core zone never have the same effect for a certain boundary condition considered. The recent unified and most comprehensive review of this subject was made by Ostrach $^{1}$ and Hoogendoorn ${ }^{2}$. Other articles on the topic published are Valencia and Frederick ${ }^{3}$, Hasnaoui et al. ${ }^{4}$, Sundstrom and Kimura $^{5}$ and Nguyen and Prudhomme ${ }^{6}$, among others, who investigated natural convection in rectangular enclosures under various configurations and orientations. Ganzarolli and Milanez ${ }^{7}$ performed numerical study of steady natural convection in rectangular enclosures heated from below and symmetrically cooled from sides. The heat source, which spanned the entire bottom wall, was either isothermal or at constant heat flux condition. Aydin and Yang ${ }^{8}$ numerically investigated the natural convection of air in a vertical square cavity with localized isothermal heating from below and symmetric cooling from sidewalls.

Few studies have been reported on natural convention in nonrectangular and non-cylindrical enclosures. For natural convection in parallelogrammic enclosures, Maekawa and Tanasawa ${ }^{9}$, Chung and Trefethen ${ }^{10}$, Naylor and Oosthuizen ${ }^{11}$, Nakamura and Asako ${ }^{12}$, and Costa et $a l{ }^{13}$ performed several investigations under different geometric orientations and boundary conditions. Besides, several earlier studies have also been performed for triangular enclosures by Akinsate and Coleman ${ }^{14}$, Poulikakos and Bejan ${ }^{15}$, Campo et al. ${ }^{16}$, Varol et al. ${ }^{17}$ and Holtzman et al. ${ }^{18}$. Asan and Namli ${ }^{19,20}$ studied the buoyant flow in a triangular roof numerically for the resembling boundary conditions of winter and summer days.

Nomenclature
$\mathrm{E} \quad$ inclined roof height, $\mathrm{m}$
$\mathrm{g} \quad$ acceleration due to gravity, $\mathrm{m} / \mathrm{sec}^{2}$
$\mathrm{~h} \quad$ convective heat transfer coefficient, $\mathrm{W} / \mathrm{m}^{2} \mathrm{~K}$
$\mathrm{H} \quad$ height of the enclosure, $\mathrm{m}$
$\mathrm{k} \quad$ thermal conductivity of the fluid, $\mathrm{W} / \mathrm{mK}$
$\mathrm{L} \quad$ width of the enclosure, $\mathrm{m}$
$\mathrm{n} \quad$ outward flux normal to boundary
$\mathrm{Nu} \quad$ average Nusselt number
$\mathrm{P} \quad$ dimensionless fluid pressure
$\mathrm{Pr} \quad$ Prandtl number
$\mathrm{q} \quad$ heat flux, W/m ${ }^{2}$
$\mathrm{Ra} \quad$ Rayleigh number
$\mathrm{T} \quad$ dimensional fluid temperature, $\mathrm{K}$
$\mathrm{u}, \mathrm{v}$ velocity components in $\mathrm{x}$ and y direction respectively,
$\mathrm{m} / \mathrm{s}$
$\mathrm{U}, \mathrm{Vdimensionless} \mathrm{velocity} \mathrm{components} \mathrm{in} \mathrm{X}$ and $\mathrm{Y}$
direction, respectively
$\mathrm{x}, \mathrm{y}$ Cartesian coordinate
$\mathrm{X}, \mathrm{Y}$ dimensionless Cartesian coordinates
Greek symbols
$\alpha \quad$ fluid thermal diffusivity, $\mathrm{m}^{2} / \mathrm{sec}$
$\beta \quad$ coefficient of volumetric expansion, $1 / \mathrm{K}$
$\eta \quad$ fluid kinematic viscosity, $\mathrm{m}^{2} / \mathrm{sec}$
$\theta \quad$ dimensionless fluid temperature
$\rho \quad$ fluid density, kg/m ${ }^{3}$
Subscript
av average
$\mathrm{c} \quad$ cold wall
ref $\quad$ reference
$\mathrm{s} \quad$ surface


The triangular top section with a rectangular enclosure is also an important concern for heat transfer studies, as it resembles a typical house or villa. Hence, various researchers have explored the analysis of natural convection in different complicated shapes of enclosures, such as a trapezoidal enclosure by Moukalled and Acharya ${ }^{21}$ and an enclosure having inclined roof by Das and $\mathrm{Sahoo}^{22}$. Morsi and $\mathrm{Das}^{23}$ investigated a square enclosure with different shaped roof tops for constant surface temperature. Recently, Saha et al. ${ }^{24}$ performed numerical study of natural convection inside a modified square enclosure having elliptical top and bottom covers.

From the above literature survey, it is found that there are some limited studies have been done for nonlinear top or bottom walled enclosure. The main interest of this investigation is to study the heat transfer for natural convection inside a modified square cavity with triangular top wall by considering the constant heat flux at one side of the vertical walls for different Rayleigh number ranging from $10^{3}$ to $10^{6}$. The other vertical wall is kept at a constant temperature and the rest of the walls i.e. the bottom wall and triangular inclined top walls are at adiabatic condition. The objective of this numerical study is to observe the comparative heat transfer characteristics between the isoflux and the isothermal heating at the vertical wall for the case of natural convection inside the modified enclosure.

\section{ANALYSIS}

The details of the geometry for the configurations considered are shown in Figure 1. A Cartesian co-ordinate system is used with the origin at the top center of the computational domain. All the considered models are a modified square enclosure with a triangular roof at the top where the left wall maintained at uniform heat flux, q. The right wall is maintained at constant cold (ambient) temperature, $T_{c}$. The rest of the boundaries are considered as adiabatic. The model is not subjected to any external flow; hence the natural convection phenomenon is studied for the present model. All the solid boundaries are assumed to be rigid with no-slip condition.

\section{Governing Equations}

A two dimensional steady-state analysis of an incompressible fluid driven by the buoyancy force is considered inside an enclosure with triangular top roof. The governing equations considered here are the same as those of Morsi and $\operatorname{Das}^{23}$. Using the Boussinesq approximation and neglecting the dissipation effect due to the viscous term, the governing equations in nondimensional form are written as follows:

$$
\begin{aligned}
& \frac{\partial U}{\partial X}+\frac{\partial V}{\partial Y}=0 \\
& U \frac{\partial U}{\partial X}+V \frac{\partial U}{\partial Y}=-\frac{\partial P}{\partial X}+\operatorname{Pr}\left[\frac{\partial^{2} U}{\partial X^{2}}+\frac{\partial^{2} U}{\partial Y^{2}}\right]
\end{aligned}
$$

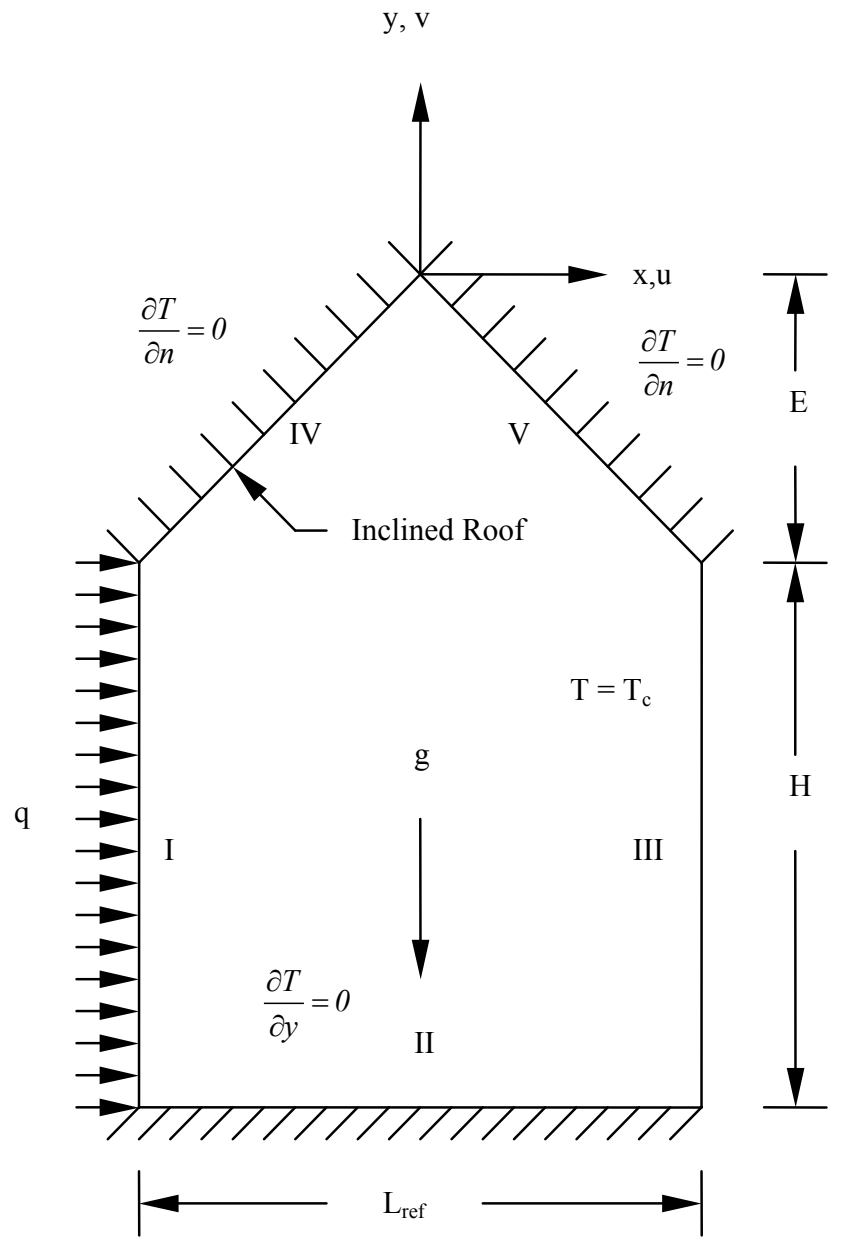

Figure 1: Schematic physical configuration and boundary conditions of the modified square enclosure 


$$
\begin{aligned}
& U \frac{\partial V}{\partial X}+V \frac{\partial V}{\partial Y}=-\frac{\partial P}{\partial Y}+\operatorname{Pr}\left[\frac{\partial^{2} V}{\partial X^{2}}+\frac{\partial^{2} V}{\partial Y^{2}}\right]+\operatorname{RaPr} \theta \\
& U \frac{\partial \theta}{\partial X}+V \frac{\partial \theta}{\partial Y}=\frac{\partial^{2} \theta}{\partial X^{2}}+\frac{\partial^{2} \theta}{\partial Y^{2}}
\end{aligned}
$$

All the above equations are normalized using the following dimensionless scales:

$$
\begin{array}{ll}
(X, Y)=\frac{(x, y)}{L_{r e f}} & (U, V)=\frac{(u, v) L_{r e f}}{\alpha} \\
P=\frac{p L_{r e f}^{2}}{\rho \alpha^{2}} & \theta=\frac{\left(T-T_{c}\right)}{q L_{r e f} / k} \\
R a=\frac{g \beta q L_{r e f}^{4}}{k \eta \alpha} & \operatorname{Pr}=\frac{\eta}{\alpha}
\end{array}
$$

Here, $\mathrm{Ra}$ is the Rayleigh number and $\mathrm{Pr}$ is the Prandtl number. The enclosure has the same height and width $(\mathrm{H}=$ $\mathrm{L}_{\mathrm{ref}}$ ) and the top inclined roof has the height $\mathrm{E}$ which is considered to have a length of 0.1 to 0.5 times $\mathrm{L}_{\text {ref }}$ in the present analysis.

\section{Boundary Conditions}

For the Navier-stokes equation, the boundary conditions are no slip at all walls and for the energy equation, the left wall is maintained at uniform heat flux q, the right wall is at uniform temperature, $T_{c}$ and the other walls are considered adiabatic. The boundary conditions and the flow domains are illustrated in Figure 1. Mathematically those can be written as non-dimensional form.

On surface of I

$$
\mathrm{U}=\mathrm{V}=0 ; \frac{\partial \theta}{\partial X}=-1
$$

On surface of III

$$
\mathrm{U}=\mathrm{V}=0 ; \quad \theta=0
$$

On surface of II, IV \& VU $=\mathrm{V}=0 ; \frac{\partial \theta}{\partial Y}=0 ; \frac{\partial \theta}{\partial \bar{n}}=0$ and $\frac{\partial \theta}{\partial \bar{n}}=0$ respectively.

The average Nusselt number, $\mathrm{Nu}$ at the heated surface is a measure of convective heat transfer coefficient. The expression for the average Nusselt number is

$$
N u=\frac{h_{a v} L_{r e f}}{k}=\frac{H}{L_{r e f}} \int_{0}^{L_{r e f} / H} \frac{1}{\theta_{s}(Y)} d Y
$$

where, $\theta_{\mathrm{s}}(\mathrm{Y})$ is the dimensionless local temperature at the heated surface.

\section{NUMERICAL ANALYSIS}

\section{Computational Procedure}

The governing equations are solved numerically using a finite element technique. A mixed finite element (FE) model is implemented with two types of triangular Lagrange element: an element with linear velocity and pressure interpolations for the continuity and momentum equations and an element with a quadratic basis velocity and temperature interpolations for the energy equation. A stationary non-linear solver is used together with Direct (UMFPACK) linear system solver. The relative tolerance for error criteria was $10^{-4}$. The non-linear equations are solved iteratively using Broyden's method with a LUdecomposition pre-conditioner, always starting from a solution for a nearby Rayleigh number. Non-uniform grids of triangular element are employed here with denser grids clustering in regions near the heat source and the enclosed walls.

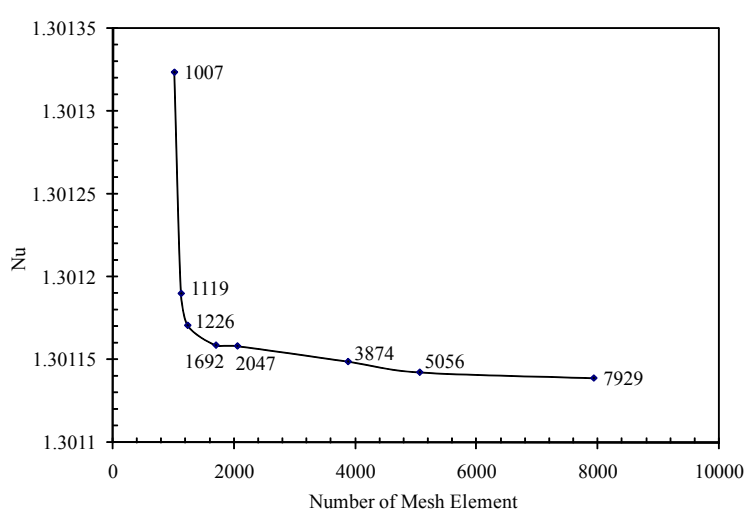

Figure 2: Convergence of average Nusselt number with mesh element for $\mathrm{Ra}=10^{3}$ and $\mathrm{E} / \mathrm{L}_{\text {ref }}=0.5$.

\section{Grid Refinement Check}

Preliminary results have been obtained to inspect the field variables grid-independency solutions. All the tests have been performed at $\operatorname{Pr}=0.71$ and $\mathrm{Ra}=10^{3}$ for the configuration of $\mathrm{E} / \mathrm{L}_{\text {ref }}=0.5$ as reported in Figure 2. Using a triangular mesh for two-dimensional simulations, eight meshes are used of which, the coarsest mesh has 1007 elements and the finest mesh has 7929 elements. Extensive numerical tests are performed and it is found that 5056 mesh elements provides satisfactory spatial resolution for the test geometry and the solution obtained is to be independent of the grid size with further refinement.

\section{Code Validation}

The computer code has been validated with the results obtained for natural convection inside the same tested model as obtained by Morsi and $\operatorname{Das}^{23}$ considering isothermal heating condition. The comparison of the results is reported in the Table 1. From the comparison, it can be seen that the computer code is capable of calculating the flow field in the present configuration.

\section{RESULTS AND DISCUSSION}

The results of this study are obtained for $\operatorname{Pr}=0.71$ and $\mathrm{Ra}=10^{3}$ to $10^{6}$ using non-uniform triangular meshes with the parametric variation of $\mathrm{E} / \mathrm{L}_{\text {ref }}$ from 0.1 to 0.5 . The resulting flow structures are analyzed to provide an idea or understanding of the effect of the Rayleigh number on the flow and the thermal fields. Important dimensionless parameter for the present study is the average Nusselt number, which has been examined to make important conclusion of the present investigation.

\section{Effect of Rayleigh number}

The development of flow and thermal fields within the modified enclosure for $\mathrm{Ra}=10^{3}$ and $10^{6}$ is presented in Figures 3 and 4, respectively for different $\mathrm{E} / \mathrm{L}_{\text {ref }}$ ratios.

\begin{tabular}{c|c|c|c}
\hline \multicolumn{3}{c}{ Table 1: Comparison of the results for the validation of the } \\
code at $\mathrm{Pr}=0.71$ and $\mathrm{E} / \mathrm{L}_{\text {ref }}=0.5$ \\
\hline $\begin{array}{c}\text { Rayleigh } \\
\text { Number }\end{array}$ & Average Nusselt number & $\begin{array}{c}\text { Error } \\
(\%)\end{array}$ \\
\cline { 2 - 3 } & Present & $\begin{array}{c}\text { Morsi and } \\
\text { Das }\end{array}$ & \\
\hline $6 \times 10^{3}$ & 2.258 & 2.247 & 0.49 \\
$8 \times 10^{4}$ & 2.456 & 2.447 & 0.37 \\
$1 \times 10^{4}$ & 2.617 & 2.601 & 0.62 \\
$2 \times 10^{4}$ & 3.171 & 3.151 & 0.63 \\
$4 \times 10^{4}$ & 3.840 & 3.81 & 0.79 \\
\hline
\end{tabular}


Since the left wall is at a higher temperature than the right wall, the density of fluid near the left wall decreases compared to the density of the fluid adjacent to the right wall, resulting in a clockwise rotation of the fluid inside the cavity as seen from those figures. For low values of Rayleigh numbers that is at $10^{3}$, the convection effect is very less and hence, the inertia forces do not make significant contribution to the heat transfer mechanism

Isotherm
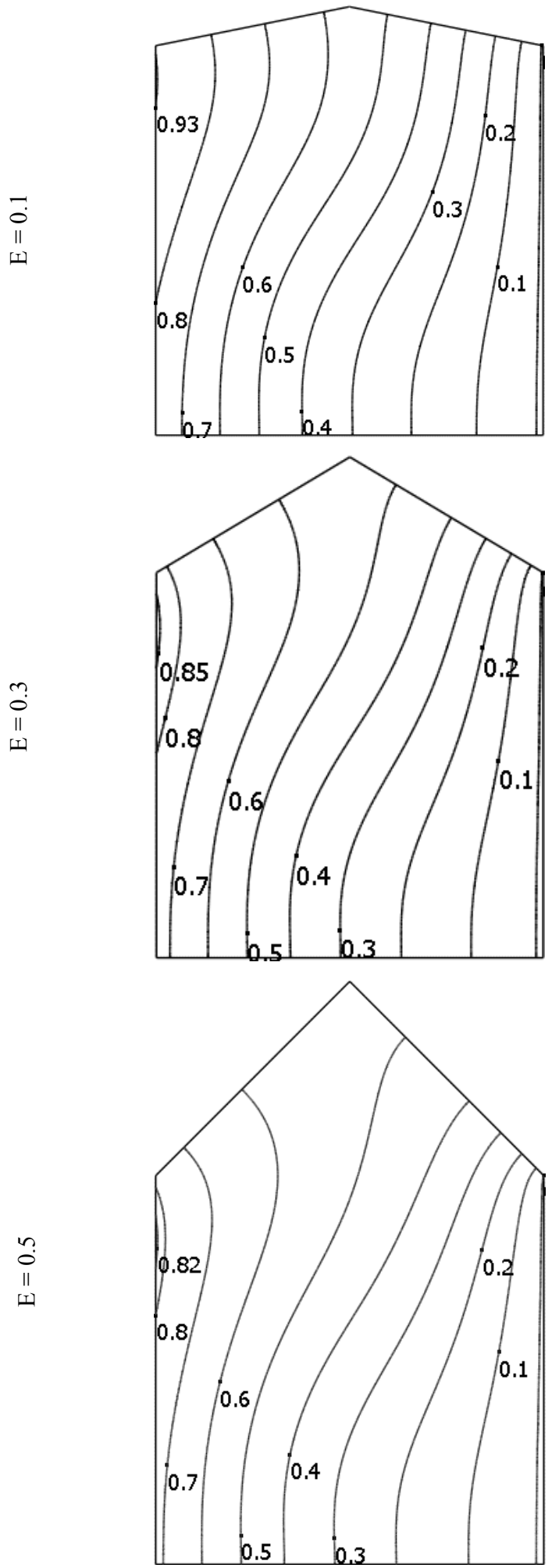

between the end walls. With the increase of the Rayleigh number, the buoyancy force increases, resulting in a strong circulation of the fluid inside the cavity and thus indicating convective heat transport as observed in Figure 4. Moreover, the streamlines of the bottom of the enclosure are more densely packed than the top of the enclosure. This is due to the geometry of the top wall.
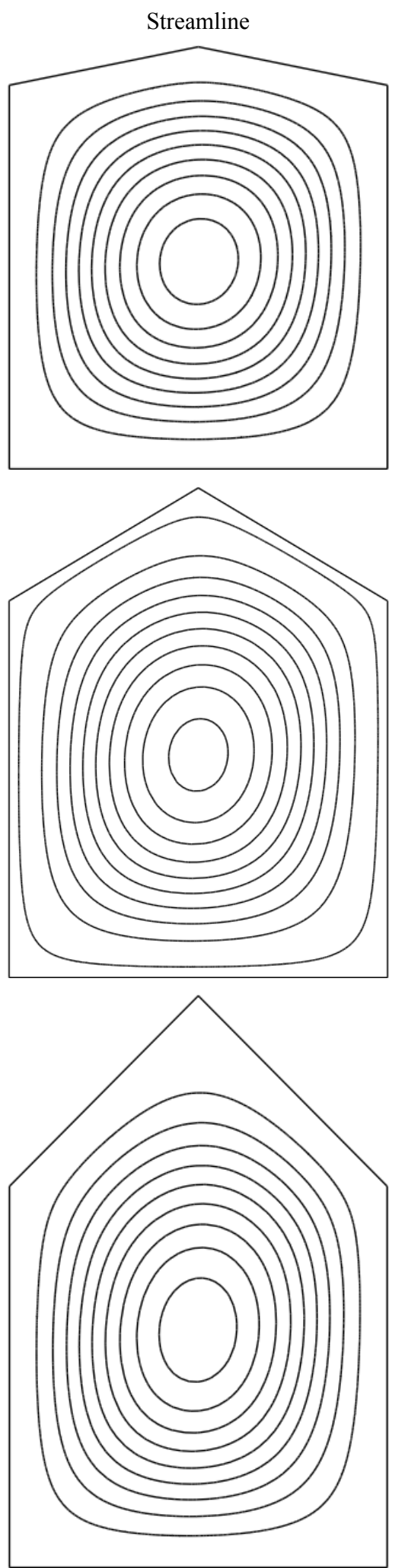

Figure 3: Isotherm and Streamline Patterns for Rayleigh Number, $\mathrm{Ra}=10^{3}$.

Journal of Mechanical Engineering, vol. ME39, No. 1, June 2008

Transaction of the Mech. Eng. Div., The Institution of Engineers, Bangladesh 
The flow is thermally stratified in the core of the enclosure for $\mathrm{Ra}=10^{3}$. No thermal stratification further appears after $\mathrm{Ra}>10^{3}$ and the isotherms are only slightly distorted by the weak flow emerging from the hot source. For lower Rayleigh number the isotherm lines are laminar like near parallel and near vertical lines. The heat transfer is purely by means of diffusion because the buoyancy force generated is not strong enough to initiate fluid convection. As the Rayleigh number increases, the nature of isotherm lines begins to deviate from that of the lower Rayleigh number. For the higher values of the Rayleigh number, the
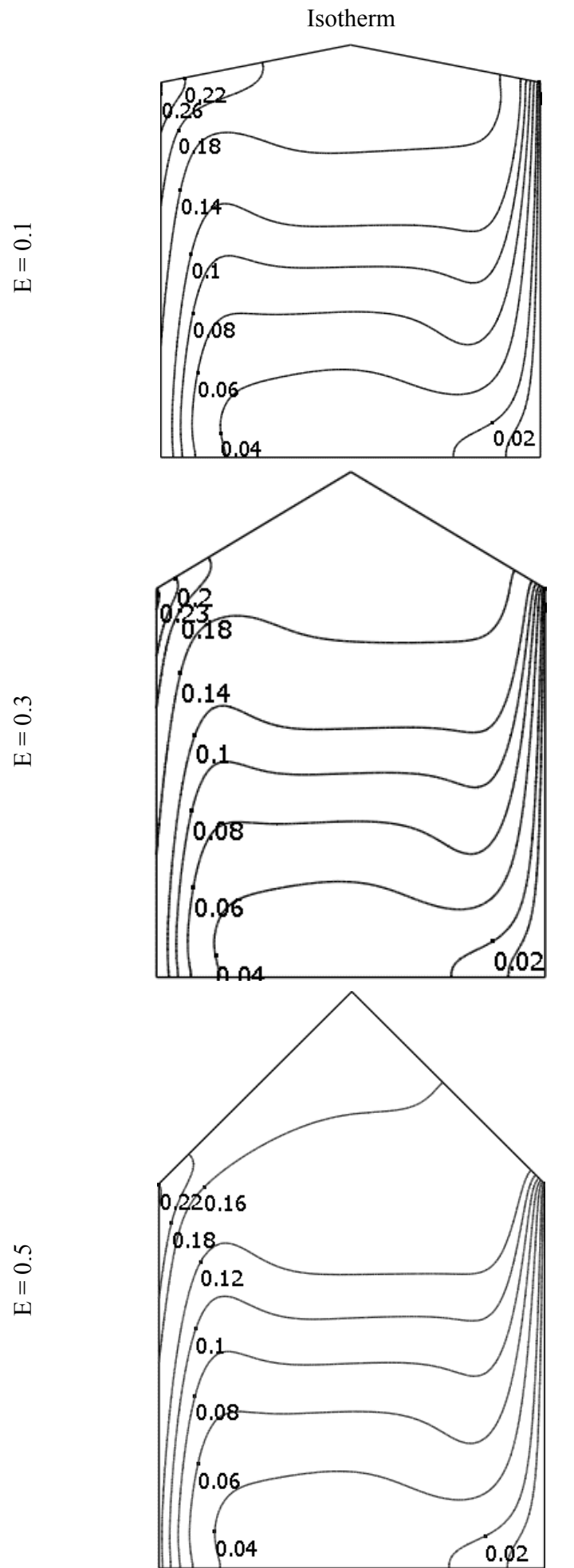

isotherm lines are a bit revolved ' $Z$ ' shaped at right angle i.e. the isotherm lines change their direction vertically at the core region. This also proves the dominance of the convective currents due to the increase of Rayleigh number. As a result, the uniformity in temperature gradient decreases and the isotherm lines become more horizontal resulting a less densely packed pattern at the core zone. Furthermore, the isotherm lines are very much packed and highly dense at the heated and cool wall. This is evident from the large temperature gradient near the heated and cold isothermal walls.

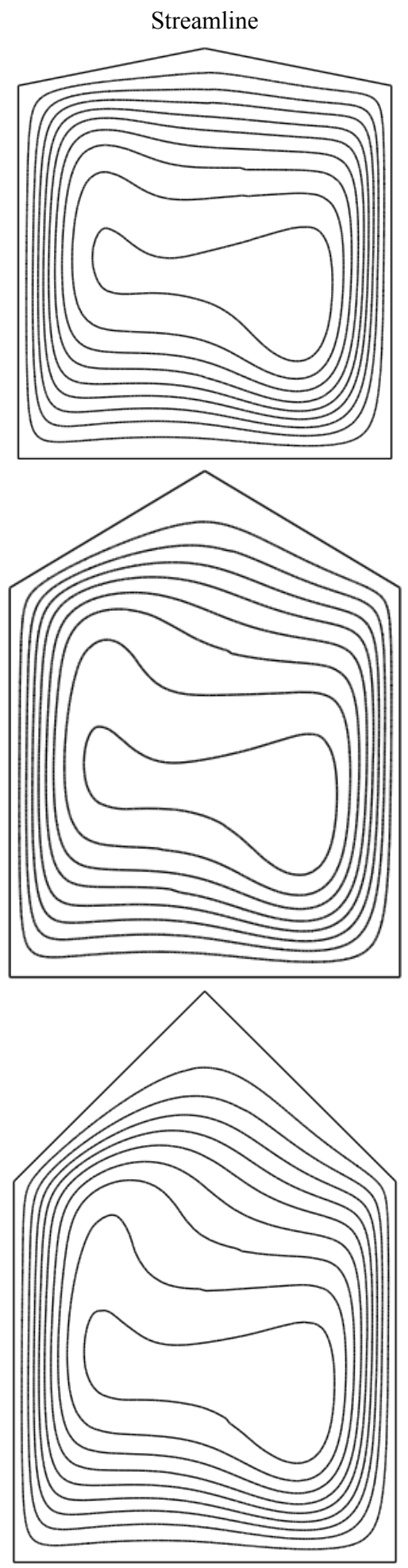

Figure 4: Isotherm and Streamline Patterns for Rayleigh Number, $\mathrm{Ra}=10^{6}$.

Journal of Mechanical Engineering, vol. ME39, No. 1, June 2008

Transaction of the Mech. Eng. Div., The Institution of Engineers, Bangladesh 


\section{Effect of Inclined Roof Height Ratio}

The buoyancy-driven flow and temperature fields inside the modified enclosure of various inclined roof height ratios are illustrated by means of contour maps of streamlines and isotherms, as exemplified in Figures 3 and 4. These figures indicate that the triangular top roof eliminate the stagnation zones at the corners and enhance the velocity of the fluid close to the vertical walls. It is also observed from these figures that the vertical velocity component is comparatively higher at high Rayleigh numbers. This is mainly due to the adiabatic triangular top roof, which allows a smooth passage to the fluid near the top boundary of the heated wall. However, when the fluid enters the triangular top roof area, it decelerates substantially, resulting in lower $U$ velocity in the central part of the triangular roof area. This is due to the fact that the flow gets a larger surface area due to the increase of $\mathrm{E} / \mathrm{L}_{\text {ref }}$ ratio, while passing from the top heated corner to the top central part of the enclosure and gently deflecting over the inclined top roof near the heated wall. This results in a weakening of the vorticity near the wall for severe change in flow direction.

\section{Heat Transfer}

A comparison of the average Nusselt number between the present isoflux heating and the previous published result of isothermal heating (Morsi and $\mathrm{Das}^{23}$ ) has been made extensively. The values of average Nusselt number have been evaluated for air $(\mathrm{Pr}=0.7)$ and for $\mathrm{Ra}$ in the range $6 \times 10^{3}$ to $4 \times 10^{4}$. The obtained values of the average Nusselt number, reported in Table 2, also reveal a good comparison among the different geometric configurations investigated here.

In case of the low $\mathrm{E} / \mathrm{L}_{\text {ref }}$ ratio, low heat transfer rates exist due to the severe deflection of flow away from the vertical walls. The insertion of the more inclined boundaries at the top wall allows the convective currents to redirect more smoothly over the triangular surface, which strongly enhances the average Nusselt number. The increase in roof height ratio, $\mathrm{E} / \mathrm{L}_{\text {ref }}$ improves the convective current for all conditions; thus a net rise in the average heat transfer rate along the heated wall is observed. In general the Nusselt number increases with the increase of Rayleigh number. Because at higher Rayleigh number the intensity of convection increase significantly resulting a significant change in the isotherm patterns. Again, the comparison of the present (iosflux heating) results with those of Morsi and $\operatorname{Das}^{23}$ shows that the average Nusselt number of the heated surface for isoflux heating is always lower than that of isothermal heating ${ }^{23}$. The reason behind this behavior is that for the case of isoflux heating the heat input per unit area is constant as the fluid moves along the heated surface. As a result, the rate of increase in the average bulk temperature of the cooling fluid with respect to flow length is constant as it moves along the surface which results a linearly increasing temperature profile for both the fluid and the surface. For the isothermal surface case, as the fluid moves along the surface and heats up, the temperature differences between the surface and the fluid begin to decrease and so the heat flux at the surface. But for the case of isoflux heating, temperature differences of the heated surface and the average bulk temperature of the fluid remain constant which pointed out lower value of the average Nusselt number compared to isothermal heating. Similar nature of these comparisons between isoflux and isothermal heating are likely to be agreed with the wellestablished results as obtained by Saha et al. ${ }^{24}$.

\section{CONCLUSIONS}

A numerical study has been carried out for a modified square enclosure with a triangular roof to observe the influence of the inclined roof height on the fluid flow and heat transfer. Some of the important outcomes of the present investigation are as follows:

(i) The study encompasses a constant value of Prandtl number 0.71 and a range of Rayleigh number from $10^{3}$ to $10^{6}$, representing the domination of convection over conduction heat transfer.

(ii) The triangular top roof height plays a significant role on the convection heat transfer mechanism. The higher the roof height, the more enhancement of heat transfers from the heated wall.

(iii) The comparison shows that the average Nusselt number for the case of isoflux heating is always less than isothermal heating.

\section{REFERENCES}

[1] Ostrach, S., 1998, "Natural Convection in Enclosures," ASME J. Heat Transfer, Vol. 110, pp. 1175-1190.

[2] Hoogendoorn, C.J., 1986, "Natural Convection in Enclosures," Proc. Eighth International Heat Transfer conference, San Francisco, Hemisphere publishing Corp, Washington, DC, Vol. 1, pp. 111120.

[3] Valencia, A. and Frederick, R.L., 1989, "Heat Transfer in Square Cavities with Partially Active Vertical Walls," Int. J. Heat Mass Transfer, Vol. 32, pp. 1567-1574.

[4] Hasnaoui, M., Bilgen, E. and Vasseur, P., 1992, "Natural Convection Heat Transfer in Rectangular Cavities Heated from Below," J. Thermophys. Heat Transfer, Vol. 6, pp. 255-264.

\begin{tabular}{|c|c|c|c|c|c|c|c|c|c|c|}
\hline \multirow{3}{*}{$\mathrm{Ra}$} & \multicolumn{2}{|c|}{$\mathrm{E}=0.1$} & \multicolumn{2}{|c|}{$\mathrm{E}=0.2$} & \multicolumn{2}{|c|}{$\mathrm{E}=0.3$} & \multicolumn{2}{|c|}{$\mathrm{E}=0.4$} & \multicolumn{2}{|c|}{$\mathrm{E}=0.5$} \\
\hline & Isothermal & Isoflux & Isothermal & Isoflux & Isothermal & Isoflux & Isothermal & Isoflux & Isothermal & Isoflux \\
\hline & $\begin{array}{c}\text { Morsi and } \\
\operatorname{Das}^{23}\end{array}$ & Present & $\begin{array}{c}\text { Morsi and } \\
\operatorname{Das}^{23}\end{array}$ & Present & $\begin{array}{c}\text { Morsi and } \\
\operatorname{Das}^{23}\end{array}$ & Present & $\begin{array}{c}\text { Morsi and } \\
\operatorname{Das}^{23}\end{array}$ & Present & $\begin{array}{c}\text { Morsi and } \\
\operatorname{Das}^{23}\end{array}$ & Present \\
\hline 000 & 1.981 & 1.805 & 2.101 & 1.872 & 2.171 & 1.919 & 2.238 & 1.952 & 2.247 & 1.975 \\
\hline 000 & 2.161 & 1.943 & 2.304 & 2.012 & 2.356 & 2.061 & 2.43 & 2.095 & 2.447 & 2.119 \\
\hline 0000 & 2.373 & 2.056 & 2.461 & 2.126 & 2.521 & 2.176 & 2.545 & 2.210 & 2.601 & 2.235 \\
\hline 0000 & 2.92 & 2.436 & 3.009 & 2.509 & 3.071 & 2.560 & 3.113 & 2.596 & 3.151 & 2.620 \\
\hline 40000 & 3.540 & 2.869 & 3.669 & 2.942 & 3.73 & 2.994 & 3.796 & 3.029 & 3.81 & 3.053 \\
\hline
\end{tabular}


[5] Sundstrom, L.G. and Kimura, S., 1996, "On Laminar Free Convection in Inclined Rectangular Enclosures," J. Fluid Mech., Vol. 313, pp. 343-366.

[6] Nguyen, T.H. and Prudhomme, M., 2001, "Bifurcation of Convection Flows in a Rectangular Cavity Subjected to Uniform Heat Fluxes," Int. Comm. Heat Mass Transfer, Vol. 28, pp. 23-30.

[7] Ganzarolli, M.M. and Milanez, L.F., 1995, "Natural Convection in Rectangular Enclosures Heated from Below and Symmetrically Cooled from Sides," Int. J. Heat Mass Transfer, Vol. 38, pp. 1063-1073.

[8] Aydin, O. and Yang, J., 2000, "Natural Convection in Enclosures with Localized Heating from Below and Symmetrically Cooling from Sides," Int. J. Numer. Meth. Heat Fluid Flow, Vol. 10, pp. 518529.

[9] Maekawa, T. and Tanasawa, I., 1982, "Natural Convection Heat Transfer in Parallelogrammic Enclosures," Proc. 7th Int. Heat Transfer Conference, Vol. 2, pp. 227-232.

[10] Chung, K.C. and Trefethen, L.M., 1982, "Natural Convection in a Vertical Stack of Inclined Parallelogrammic Enclosures," Int. J. Heat Mass Transfer, Vol. 25(2), pp. 277-284.

[11] Naylor, D. and Oosthuizen, P.H., 1994, “A Numerical Study of Free Convective Heat Transfer in a Parallelogram-Shaped Enclosure," Int. J. Numer. Meth. Heat Fluid Flow, Vol. 4, pp. 553-559.

[12] Nakamura, H. and Asako, Y., 1982, "Heat Transfer in a Parallelogram shaped Enclosure," Bull JSME, Vol. 25, pp. 1412-1418.

[13] Costa, V.A.F., Oliveira, M.S.A. and Sousa, A.C.M., 2005, "Laminar Natural Convection in a Vertical Stack of Parallelogrammic Partial Enclosures with Variable Geometry," Int. J. Heat Mass Transfer, Vol. 48, pp. 779-792.

[14] Akinsate, V.A. and Coleman, J.A., 1982, "Heat Transfer by Steady State Free Convection in Triangular Enclosure," Int. J. Heat Mass Transfer, Vol. 25, pp. 991-998.

[15] Poulikakos, D. and Bejan, A., 1983, "Natural Convection Experiments in a Triangular Enclosure," ASME J. Heat Transfer, Vol. 105, pp. 652-655.
[16] Campo, E. M., Sen, D.M. and Ramos, E., 1988, "Analysis of Laminar Natural Convection in Triangular Enclosure," Numerical Heat Transfer, Vol. 13, pp. 353-372.

[17] Varol, Y., Koca, A. and Hakan F., 2006, "Natural Convection in a Triangle Enclosure with Flush Mounted Heater on the Wall," Int. Comm. Heat Mass Transfer, Vol. 33, pp. 951 - 958.

[18] Holtzman, G.A., Hill, R.W. and Ball, K.S., 2000, "Laminar Natural Convection in Isosceles Triangular Enclosure Heated From Below and Symmetrically Cooled From Above," ASME Journal of Heat Transfer, Vol. 122, pp. 485-491.

[19] Asan, H. and Namli, L., 2001, "Numerical Simulation of Buoyant Flow in a Roof of Triangular Cross-section under Winter Day Boundary Condition," Energy and Building, Vol. 33, pp. 753 757

[20] Asan, H. and Namli, L., 2001, "Laminar Natural Convection in a Pitched Roof of Triangular Crosssection: Summer Day Boundary Condition," Energy and Building, Vol. 33, pp. $69-73$.

[21] Moukalled, F. and Acharya, S., 1997, "Buoyancyincluded Heat Transfer in Partially Divided Trapezoidal Cavities," Numerical Heat Transfer, Part A, Vol. 32, pp. 787-810.

[22] Das, S. and Sahoo, R., 1998, "Velocity-Pressure Formulation for Convective Flow inside Enclosure with Top Quadratic Inclined Roof," J. Energy Heat Mass Transfer, Vol. 20, pp. 55-64.

[23] Morsi, Y.S. and Das, S., 2003, "Numerical Investigation of Natural Convection inside Complex Enclosures," Heat Transfer Engineering, Vol. 24(2), pp. 30-41.

[24] Saha, G., Saha, S. and Islam, M.Q., 2007, "Natural Convection in a Modified Square Enclosure with Constant Flux Heating From Left," AIUB J. Science Engineering, Vol. 6(1), pp. 89-96. 